University of Louisville

ThinkIR: The University of Louisville's Institutional Repository

Electronic Theses and Dissertations

$12-2019$

\title{
Aisle design for order picking operations with unit-load replenishment.
}

Dominic lan Sleigh

University of Louisville

Follow this and additional works at: https://ir.library.louisville.edu/etd

Part of the Industrial Engineering Commons

\section{Recommended Citation}

Sleigh, Dominic lan, "Aisle design for order picking operations with unit-load replenishment." (2019).

Electronic Theses and Dissertations. Paper 3358.

https://doi.org/10.18297/etd/3358

This Master's Thesis is brought to you for free and open access by ThinkIR: The University of Louisville's Institutional Repository. It has been accepted for inclusion in Electronic Theses and Dissertations by an authorized administrator of ThinkIR: The University of Louisville's Institutional Repository. This title appears here courtesy of the author, who has retained all other copyrights. For more information, please contact thinkir@louisville.edu. 


\title{
AISLE DESIGN FOR ORDER PICKING OPERATIONS WITH UNIT-LOAD REPLENISHMENT
}

\author{
By \\ Dominic Ian Sleigh \\ B.A., University of Louisville, 2018 \\ MEng, University of Louisville, 2019 \\ A Thesis or Dissertation \\ Submitted to the Faculty of the \\ University of Louisville J.B. Speed School of Engineering \\ in Partial Fulfillment of the Requirements \\ for the Degree of \\ Master of Science \\ in Industrial Engineering \\ J.B. Speed School of Engineering \\ University of Louisville \\ Louisville, Kentucky
}

December 2019 



\section{AISLE DESIGNS FOR ORDER PICKING OPERATIONS WITH UNIT-LOAD REPLENISHMENT}

Submitted by:

Dominic Ian Sleigh

A Thesis Approved on

(Date)

by the Following Reading and Examination Committee:

Kevin R. Gue, Thesis Director

John S. Usher

Csaba Biró 


\section{ABSTRACT \\ AISLE DESIGN FOR ORDER PICKING OPERATIONS WITH UNIT-LOAD REPLENISHMENT \\ Dominic Ian Sleigh}

November 22, 2019

The warehouse design problem has been addressed in the last decade with fewer constraints than ever before. Between optimization for unit load and order picking warehouses, the former has had extensively more research performed. Unit load optimization efforts have promised labor savings of $20-22 \%$. Of the existing research for order-picking warehouses, only small improvements of less than $4 \%$ have been claimed. We propose the design optimization for order-picking warehouses requires consideration for inherently incurred unit load operations from pallet inbound activities, as well as forward-pick area replenishment. We perform experiments comparing optimization of aisle design using order picking data with and without the inclusion of unit load operations. While no great improvements over current designs are found with our experiments, we develop our theory for application. Additionally, we explore the relationship of travel distance reduction between unit load and order picking operations. 


\section{TABLE OF CONTENTS}

\section{PAGE}

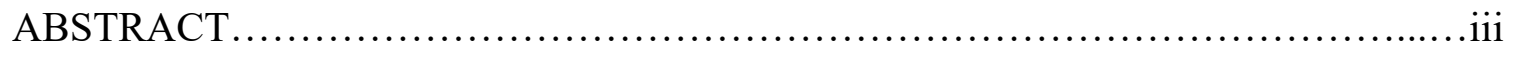

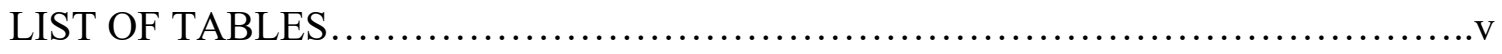

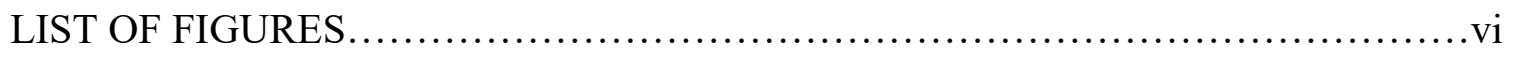

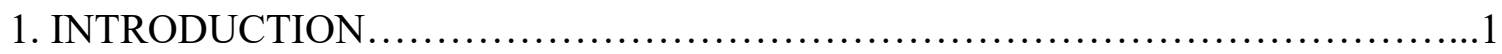

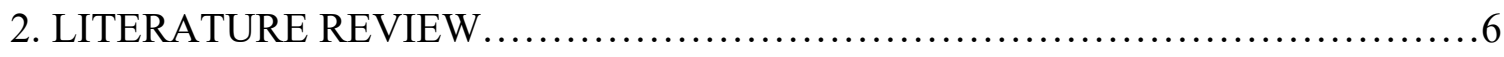

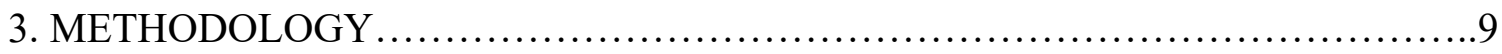

3.1 Computational Method....................................................

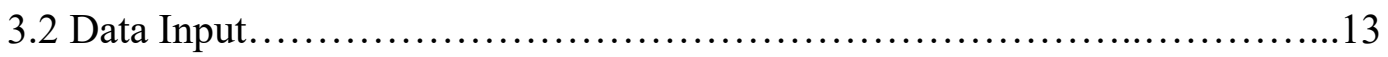

3.3 Unit Load Addition....................................................... 15

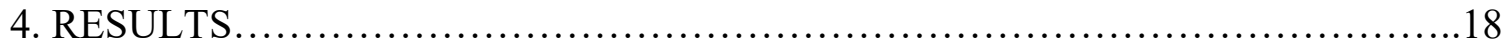

4.1 Layouts Optimized for Order Picking (Type 1), A-F........................19

4.2 Layouts Optimized for Order Picking and Unit Load (Type 2), A-F...........21

4.3 Manually Created Layouts (Type 3) A-D ................................23

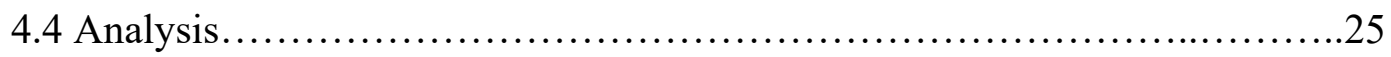

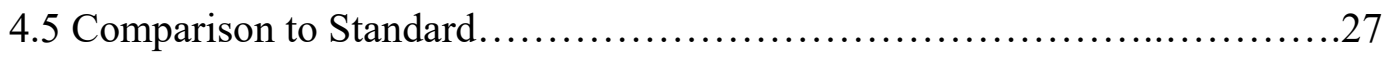

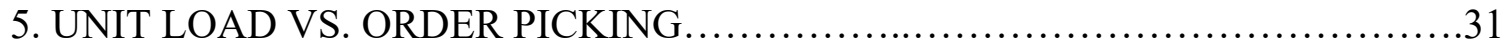

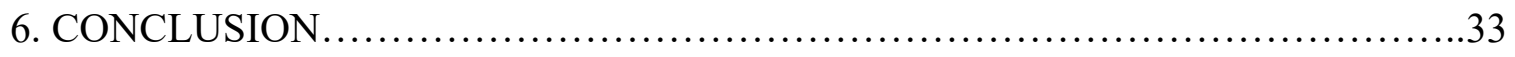

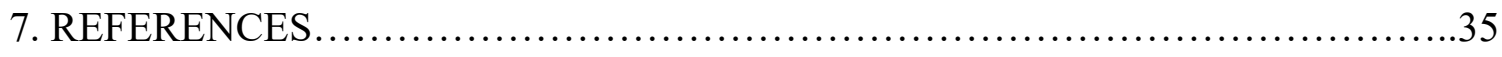




\section{LIST OF TABLES}

TABLE PAGE

1. Data for Verification of 800 Order Samples......................................14

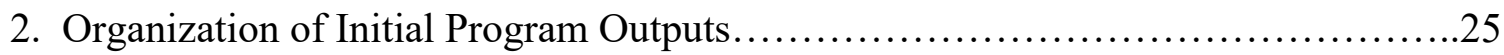

3. Matrix of Average Travel Distance Values with Data Input, Layout and Seed.........26

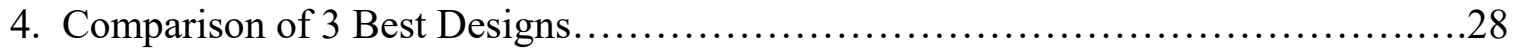

5. Order Picking Vs. Unit Load Average Travel Distance...............................32 


\section{LIST OF FIGURES}

FIGURE PAGE

1. Standard Warehouse Layouts (with zero and one cross aisle, respectively)...........2

2. Graphic from www.warehouse-science.com for forward pick areas................4

3. Full population run with replenishment data................................ 12

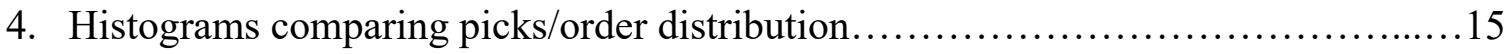

5. Layout type 1, A............................................................ 19

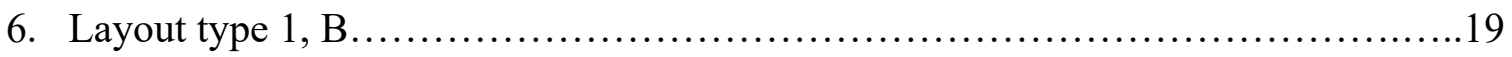

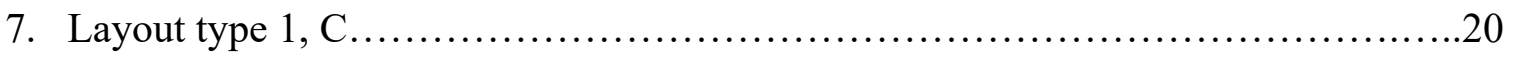

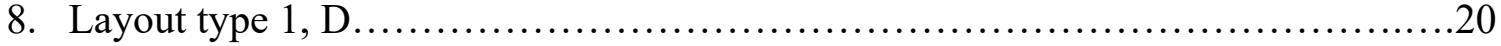

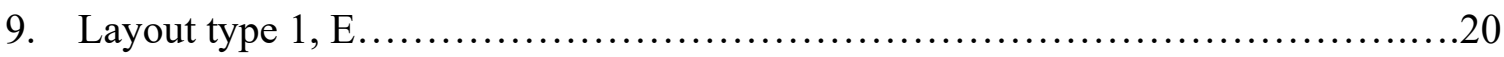

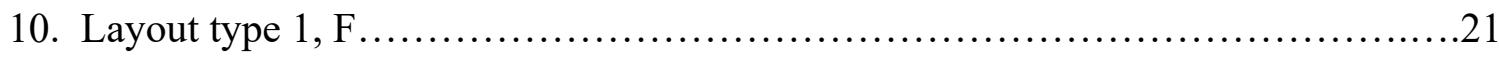

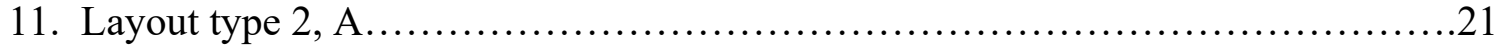

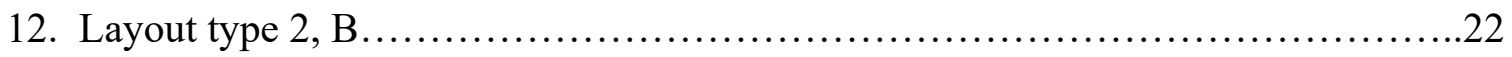

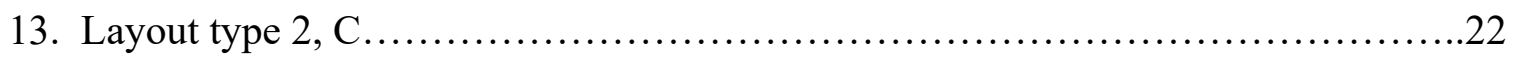

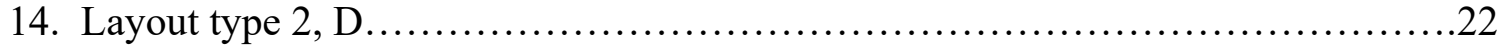

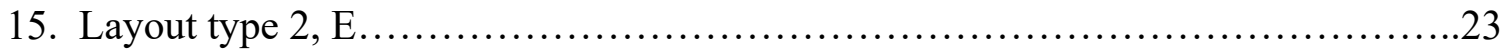

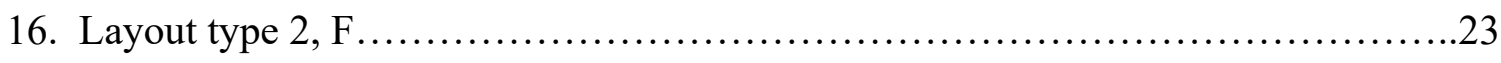

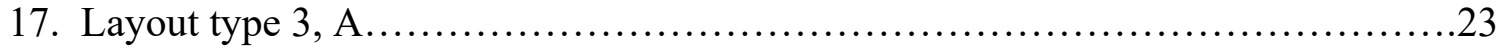

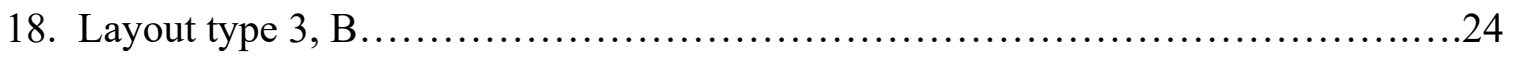

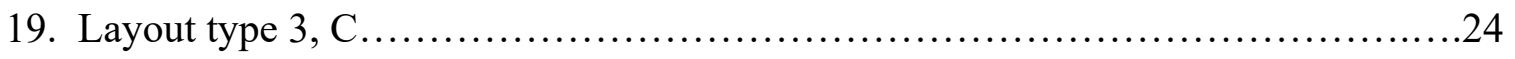

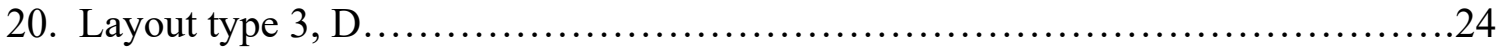

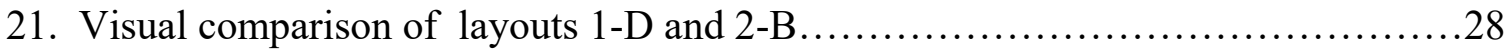

22. Result of manually modifying attributes of layouts $1-\mathrm{D}$ and $2-\mathrm{B} \ldots \ldots \ldots \ldots \ldots \ldots . \ldots . \ldots . . .29$ 


\section{INTRODUCTION}

A standard for warehouse layout design has existed nearly unquestioned throughout the industrial age. The standard consists of multiple parallel storage aisles, creating a rectangular storage area (See Figure 1). Some such warehouses have one or two crossaisles that are usually perpendicular to the storage aisles. In the past 50 years, scientific literature has come to question if there exists more efficient designs than the standard with respect to average travel distance or travel time for warehouse operators. Gue and Meller (2009) created new layouts for warehouses using single command unit load operations that questioned unwritten rules of warehouse design by introducing nonparallel storage aisles and angled or curved cross-aisles in a variety of ways. Since then, more attempts at optimizing warehouse layouts for average worker travel distance have been made by disregarding standard layout presuppositions (Ozden 2017, Bortolini, 2018). However, all such attempts have been made considering either unit load or order picking operations individually. We seek to generate and evaluate warehouse layout options with both picking types considered realistically. 

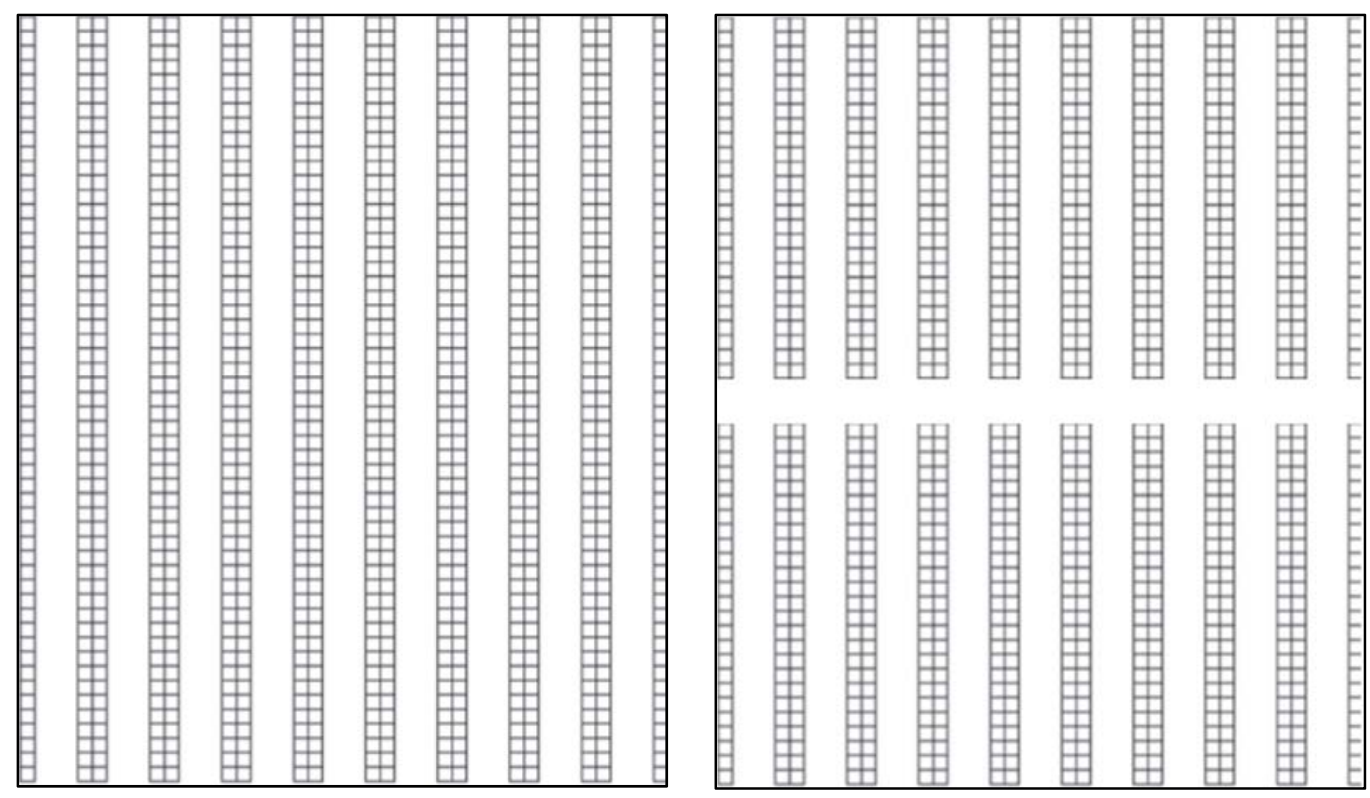

Figure 1. Standard warehouse layouts (with one and two cross aisle, respectively)

In order to fully explain the methodology of this research, we will first define the two types of picking in warehousing, and then explain the nuances of these classifications that hold crucial to our work in the beginning of the Methodology section. Two types of warehouses exist from an operational, product retrieval perspective: unit load and order picking. For unit load operations, workers typically move entire pallets, resulting in one movement into the storage facility, and one movement back out; this is known as single command unit load. Dual command unit load operations also exist, in which an operator can perform one movement of goods into the facility and retrieve another pallet of goods for shipment on the way back. For order picking operations, workers may travel into the storage facility and visit multiple locations before heading back. This is because these operations are requested by order tickets calling for individual items off of pallets.

With different movement types required of both types of operation, certain features within a storage facilities' layout can provide different levels labor savings or cost to a warehouse. The primary design feature is the cross-aisle and its position and 
angle. Vaughan (1999) defined the cost of implementing cross-aisles as "the loss of storage space taken up by cross aisles within a given size facility" with the benefit of increase flexibility workers have when obtaining items from multiple aisles. A warehouse that requires only unit load operations has no need for a cross-aisle in traditional design, because at no point should a worker need to travel between aisles during a pick, with the exception of dual-command unit load operations. At this point, cross-aisles would more often incur only a cost. This premise is important as a distinction between benefit differences of unit load and order picking operations as we use the combination of both experimentally.

Many order picking storage facilities use a forward picking area, which is the portion of most quickly accessible storage locations to be dedicated to the typically faster moving goods (Bartholdi and Hackman, 2011). Typically, this is seen as the bottom level of storage racks, because more time is required for a worker to pick from higher levels. The benefit of assigning high-volume SKUs into the forward picking area as labor savings from short pick times for multiple SKU location visits. This benefit comes at the cost of labor required for a worker to take a pallet from a reserve location (longer pick time) to restock the forward area. If the time savings from multiple picks are greater than the single restock time for all SKUs in the forward area, then labor savings are made. This is commonly the case for many warehouses, and therefore is included as an assumption for our work. 


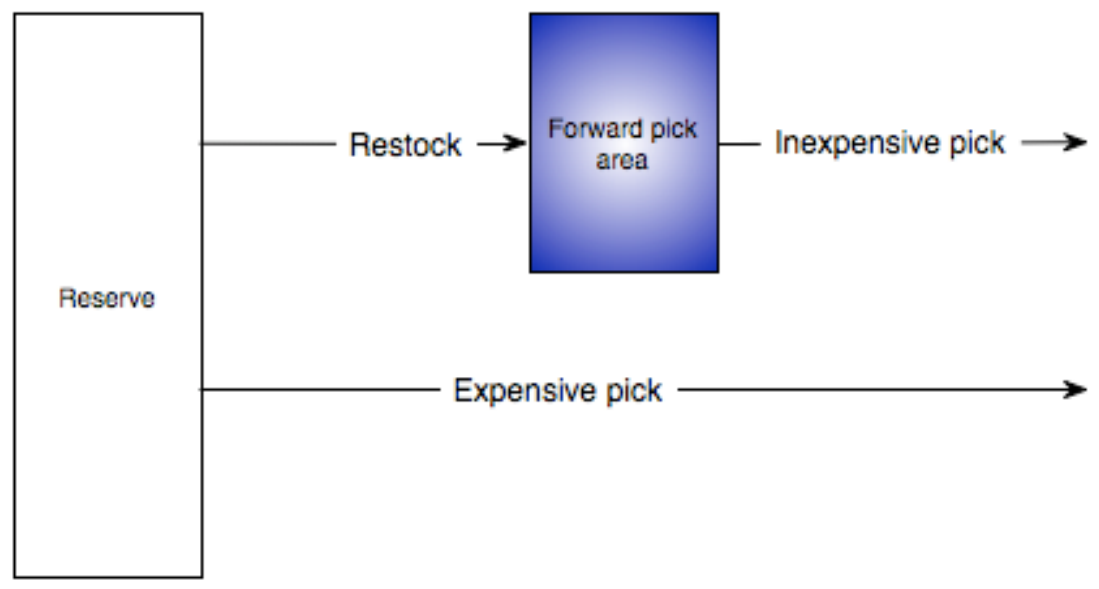

Figure 2. Graphic from www.warehouse-science.com for forward pick areas Very few order picking warehouses operate with only order picking activities. This is because every pallet depleted from a forward pick area incurs 2 unit load operations: one for receiving and putting away a new pallet to the warehouse and one to replenish the forward pick area. Therefore, order picking warehouses should be evaluated as a combination of both unit load and order picking activities when using optimization programs or heuristics for layout solutions.

Furthermore, the inclusion of a cross aisle in a standard warehouse does not yield a reduction in travel distance (and may actually increase travel distance) for a unit load operation, but it can reduce total travel distance in order picking tours. When picking items in multiple locations in a single tour, an order picker may be closer to a cross aisle than an aisle end when needing to move to another storage aisle. With this example alone, it is reasonable to assume that optimizing warehouse design for order picking without the inclusion of unit load operations may include, reject or modify features that may provide travel distance reductions across all warehouse operations. 
The consideration of both picking types must then be important for finding solutions for real world applications. When considering a layout for an order picking warehouse, the effect of using only order picking in the analysis of warehouse design could cause an overemphasis on features that only reduce labor for multi-pick trip operations, rather than finding the optimal balance of characteristics for all warehouse labor. Our research seeks to determine if using both unit load and order picking data reveals layouts with greater labor improvements over previous designs than has been found thus far. 


\section{LITERATURE REVIEW}

A review of the literature shows that research has typically explored simple modifications to the standard warehouse layouts for shortly over 50 years and has progressed to questioning nearly all aspects of modern warehousing. Our research aligns with the more unconstrained exploration of layout possibilities presented by Gue and Meller (2009). We explore unit load research in this work because such operations will be simulated along with order picking operations.

Our analysis uses software designed by Ozden (2017). This software allows for most design constraints to be relaxed. This includes parallel storage aisles and perpendicular cross-aisles. The program is described in greater detail in the Methodology section. In comparison to the literature, the use of this program will allow procedural modification and evaluation based on order data to drive the generation of the layout. This is alternative to the common heuristic approach to layout creation. Additionally, using this program means the produced layouts will be optimized for specific data, rather than merely testing data in a design for general operation. 
White (1972) was one of the first to investigate the aisle design problem. This work was very unique for its time, as it also relaxed the constraints of parallel storage aisles and perpendicular cross aisles, long before they were explicitly defined by Gue and Meller (2009). After that point, the possibilities of alternative warehouse layouts have been revisited in some new ways. We do not aim to explore them chronologically, but rather in increasing order of relevance to our work.

Others have investigated warehouse size and dimension as attributes for optimization (Francis, 1967, Bassan, Roll and Rosenblatt, 1980, Roberts, 1968). Kallina and Lynn (1976), and Jarvis and McDowell (1991) addressed product assignment issues. Storage and picking methods were investigated by Berry (1968), Ratliff and Rosenthal (1983), and Matson and White (1981). Bortolini et al (2015) sought to optimize the count and angle of diagonal cross-aisles in warehouses based on warehouse size and dimension. Afterward, Bortolini, Marco, et al (2019) explored class-based storage with diagonal cross-aisles. Both of these works were in consideration for single-command unit load operations but did relax the constraint of perpendicular cross aisles.

Single-command unit load research has shown diagonal cross-aisles such as in the fishbone layout to yield significant improvements in travel distance for picks. The literature shows that optimizing these designs is less effective with dual-command unit load operations. This is shown by Pohl, Meller, Gue (2009) that the fishbone aisle, which previously boasted $20 \%$ labor reduction on single-command operations by Gue and Meller (2009) and presents 10-15\% reduction with dual-command unit load.

The literature for order picking warehouse layout optimization is very limited. Öztürkoğlu, Ö., \& Hoser, D. (2019) explore the order picking cross-aisle design problem 
heuristically, maintaining standard design constraints with storage aisles and cross aisles. However, their work uses discontinuous cross-aisles referred to as "tunnels" at different points along the lengths of each aisle.

Ozden (2017) presents research most similar to ours. His work is important because it makes no presuppositions concerning an optimal layout and allows data to drive the evolution of a layout. This work also explores the order picking aisle design problem with a wide range of possibilities. The layouts suggested in his research show minimal improvement over standard layouts, with travel distance improvements up to only $4 \%$. This is much smaller than the improvements of $20 \%$ and $15 \%$ for single command and dual command unit load operations, respectively. If improvements for unit load operations hold greater potential for improvement than that of order picking operations, then it is also reasonable to assume that the inclusion of unit load operations may increase potential travel distance improvement. 


\section{METHODOLOGY}

Warehouse size and dimension, along with storage and retrieval techniques have been used as metrics on which to base design decisions, as cited in the previous section. We propose that the ratio of the order picking to unit load operations should also determine optimal design. With the necessity for the inclusion of unit load operations for order picking design optimization, a method of defining the proportion of activity between the two types of operations must exist.

Most order picking warehouses use a forward pick area, therefore we assume the existence of one for our methodology. Pallets from the forward pick area only incur the two unit load activities, replenishment and receiving, when they are depleted. Pallets are only depleted upon having their total number of units (cartons, items, boxes etc.) taken by multiple individual picks over time. Therefore, two metrics define the ratio of unit load to order picking activities for a given SKU: the average number of picks that SKU receives per order and the maximum number of units on a pallet for that SKU.

More importantly, the summation of the metric across all SKUs defines the ratio of unit load to order picking activities. The summation for the two metrics is the following: the average number of picks per order, and the average of the maximum

number of units per pallet. The ratio of the two, $\frac{(\text { Picks/order })}{(\text { Units/Pallet })}$, can be used to 
calculate the average number of pallets depleted per order picking tour. Simplifying the fraction to (Pallets/Order) proves this, assuming 1 pick is equivalent to 1 unit.

We abbreviate this ratio of $\frac{(\text { Picks/Order })}{\text { (Units/Pallet) }}$ or (Pallets/Order) as $\alpha$. If $\alpha$ represents the ratio of pallet depletions to order picking tours, and each pallet depletion results in 2 unit load activities, 1 for replenishment and 1 for receiving, then $2 \alpha$ must represent the ratio of order picking tours to unit load operations. For example, if a warehouse worker picks an average of 10 different items per order picking tour, and pallets in that warehouse have an average of 20 units at max capacity, then $\alpha=10 / 20=1 / 2$. On average, half a pallet is depleted per order picking tour, or one pallet is depleted every 2 order picking tours. Also, $2 \alpha=2(1 / 2)=1$, meaning that for every order picking tour in this warehouse, one unit load operation is incurred. In such a situation, it is apparent how not including unit load activities may significantly misrepresent actual labor.

Order pickers would likely not carry more units than can fit on a pallet, meaning that for $\alpha$ there must exist a maximum at 1 . It can be also be assumed that order picking tours will pick more than 0 pallets per tour. Therefore, the following must be true:

$$
0<\alpha \leq 1
$$

The low end of this range probably has few realistic cases, as warehouses with low $\alpha$ must be running very inefficiently by carrying only a small fraction of a pallet's worth of units, either due to worker carrying capacity constraints or small order sizes. Very high values for $\alpha$ are probably uncommon as well because however small the items are to allow for a great carrying capacity of workers and a large (Picks/Order), then the same increase of capacity due to item size will apply to the pallet, meaning that pallets of 
that item will have a large (Units/Pallet). In other words, it's reasonable to assume that (Picks/Order) and (Units/Pallet) are positively correlated.

\section{COMPUTATIONAL METHOD}

The layout generation portion of this research is performed using a specialized software developed by Ozden (2017) for the purpose of researching alternative design. The program analyzes order data, ranks SKUs by demand, generates a random layout and distributes the SKUs locations by order of rank. The program then uses multiple Travelling Salesman Problems to determine the average travel distance per order. Using this average travel distance as a fitness function, the program uses evolutionary programming to modify the layout randomly, test the fitness again, explore the space of designs with bias for characteristics that yield improvement to the fitness function. The output folder at the end of the run contains each layout found to be advantageous over the previous iteration, and its associated data. The final layout is the most efficient one found for the order data input in the program run time.

The evolutionary programming is intended to mimic the problem-solving nature of natural evolution (Ozden 2017). In this case, a random layout is created, evaluated for fitness (with average travel distance using the order data input), mutated and then evaluated again. If the mutated layout is superior, the old layout is recorded, and the mutations are applied to the new layout. For each mutation, multiple parameters are modified by a value within a normal distribution, and if a child layout is superior to its parent, a new mutation is applied to the child with a greater standard deviation for the normal distribution from which parameters are modified. 
This effect both homes in on effective attributes, allowing only small changes to be made once an improvement is found, and for increasingly large changes as no new nearby improvements can be found. One strength of this method is that the generation of optima uses a fitness function rather than an objective function. The program is able to mutate the following attributes during optimization (these can be seen in Figure 3): width/depth ratio, cross aisle count (up to 5), cross aisle angle and location, I/O location, storage aisle angle.

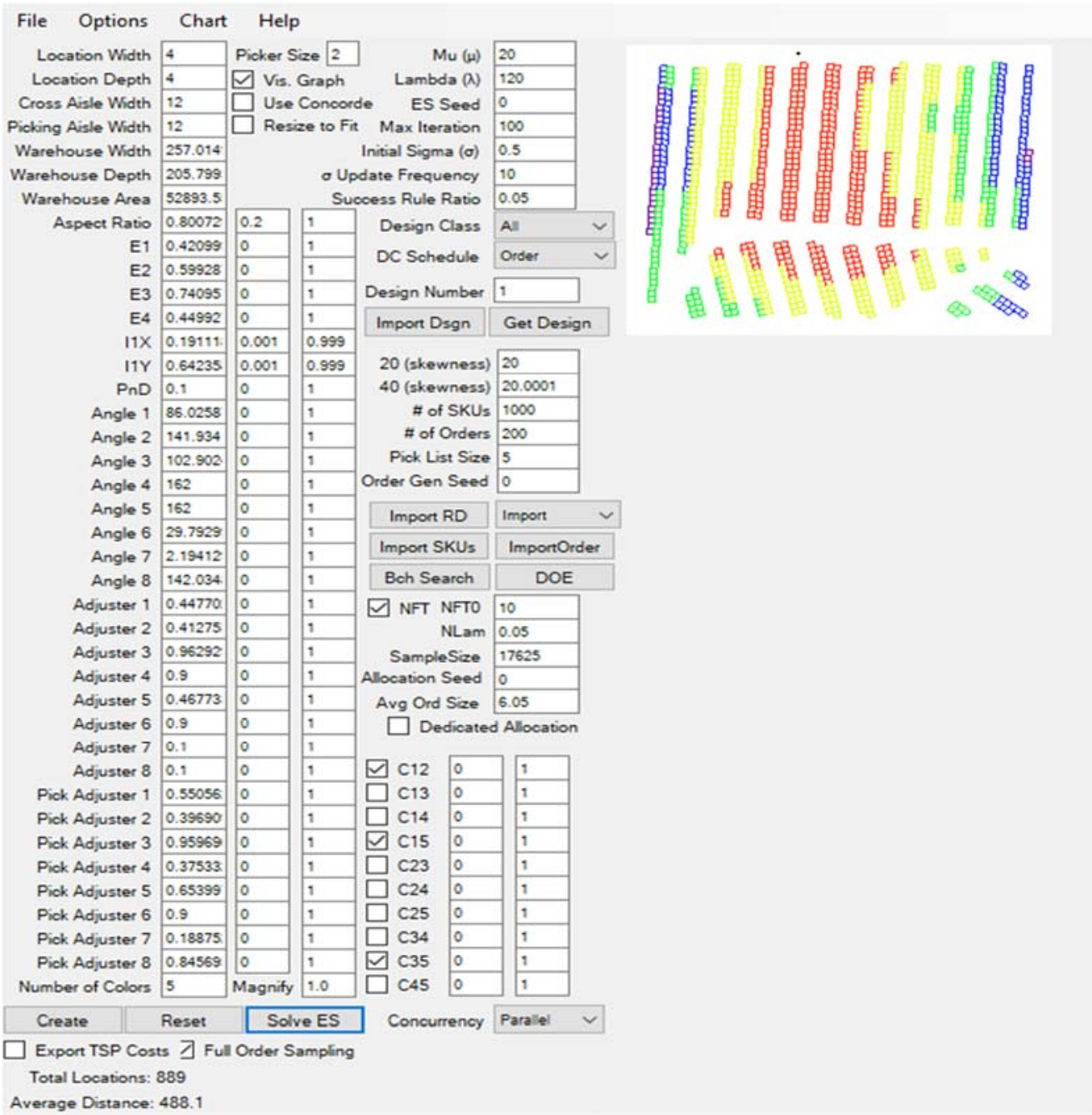

Figure 3. Full population run with replenishment data 
The program allows the parameters of the layout to be edited manually, allow the user to evaluate specific layouts. We use this to test each layout with both order picking data and the composite order picking and unit load data. Figure 3 shows the screen of the program.

\section{DATA INPUT}

Our experimental data contains 10,967 orders in 99,999 order lines for an average of 9.118 lines per order. The data consists of 887 SKUs and comes from a large distributor. In order to better utilize the information for the purpose of this work, orders with fewer than 5 picks were removed, leaving 6,339 orders, 90,196 lines and 834 unique SKUs with an average of 14.228 picks/order. For computational reasons, the order count needed to be reduced by a factor of nearly 8 . We rounded this value to 800 orders.

In order to verify that the smaller data set fairly represents the original, we test the 800 -order size in 4 different ways with 10 random samples: by mean picks/order, unique SKU count, picks/order histogram comparison and Mean Absolute Percentage Difference (MAPD) between the program outputs with each sample tested on a standard warehouse. All comparison methods are used in the validity testing of the samples and will also be used in selecting the best sample to use as the program input. Comparison of the smaller data sets against the population by comparison of average total distance when tested on a pre-defined standard layout would be a very direct verification method but proves to be impossible given that the samples had largely different SKU quantities and unique SKU sets from the population.

The random samples are created using a random number generator. The metrics below in Table 1 were gathered from the first 10 samples, and the distance output was 
obtained by inputting each sample to be evaluated for average travel distance in a standard warehouse with no cross aisles, adjusted in size for the number of SKUs/storage locations for each sample.

\begin{tabular}{|c|c|c|c|c|c|c|c|c|c|c|c|}
\hline & & & & & & Sample & & & & & \\
\hline & 1 & 2 & 3 & 4 & 5 & 6 & 7 & 8 & 9 & 10 & Avg. \\
\hline \begin{tabular}{c|} 
Mean \\
Picks/Order
\end{tabular} & 14.43 & 14.38 & 13.46 & 13.67 & 13.92 & 14.19 & 15.03 & 14.77 & 14.00 & 14.3 & 14.21 \\
\hline SKU Count & 686 & 691 & 675 & 671 & 651 & 714 & 692 & 710 & 702 & 675 & 686.7 \\
\hline $\begin{array}{c}\text { Distance } \\
\text { Output }\end{array}$ & 1035.2 & 1031.3 & 1020.6 & 1005.8 & 1037.6 & 1058.3 & 1030.4 & 1023.4 & 1007.3 & 1021 & 1027.1 \\
\hline Difference & 8.11 & 4.21 & -6.49 & -21.29 & 10.51 & 31.21 & 3.31 & -3.69 & -19.79 & -6.09 & 0 \\
\hline $\begin{array}{c}\text { Abs. } \\
\text { Difference }\end{array}$ & 8.11 & 4.21 & 6.49 & 21.29 & 10.51 & 31.21 & 3.31 & 3.69 & 19.79 & 6.09 & 11.47 \\
\hline $\begin{array}{c}\text { \% Abs. } \\
\text { Difference }\end{array}$ & $0.79 \%$ & $0.41 \%$ & $0.63 \%$ & $2.07 \%$ & $1.02 \%$ & $3.04 \%$ & $0.32 \%$ & $0.36 \%$ & $1.93 \%$ & $0.59 \%$ & $1.12 \%$ \\
\hline
\end{tabular}

Table 1. Data for Verification of 800 Order Samples

The results show an MAPD of $1.12 \%$, demonstrating a relatively small variation between samples, suggesting that random samples of the population are consistent in terms of average order pick time for identical warehouses. The results also show that the average of sample picks/order means is 14.21 , only 0.01 less than the population mean of 14.22. The unique SKU count decreases considerably, from 834 to a mean of 686.7 .

To confirm similarity of picks/order distribution, histograms of samples were adjusted in scale to match the population. These proved to be highly similar. It is reasonable to assume the likeness of sample 6 to the population, its high SKU count and high distance output are all related. With more storage locations comes higher average travel distances due to product being stored in added locations along the outside of the warehouse. 


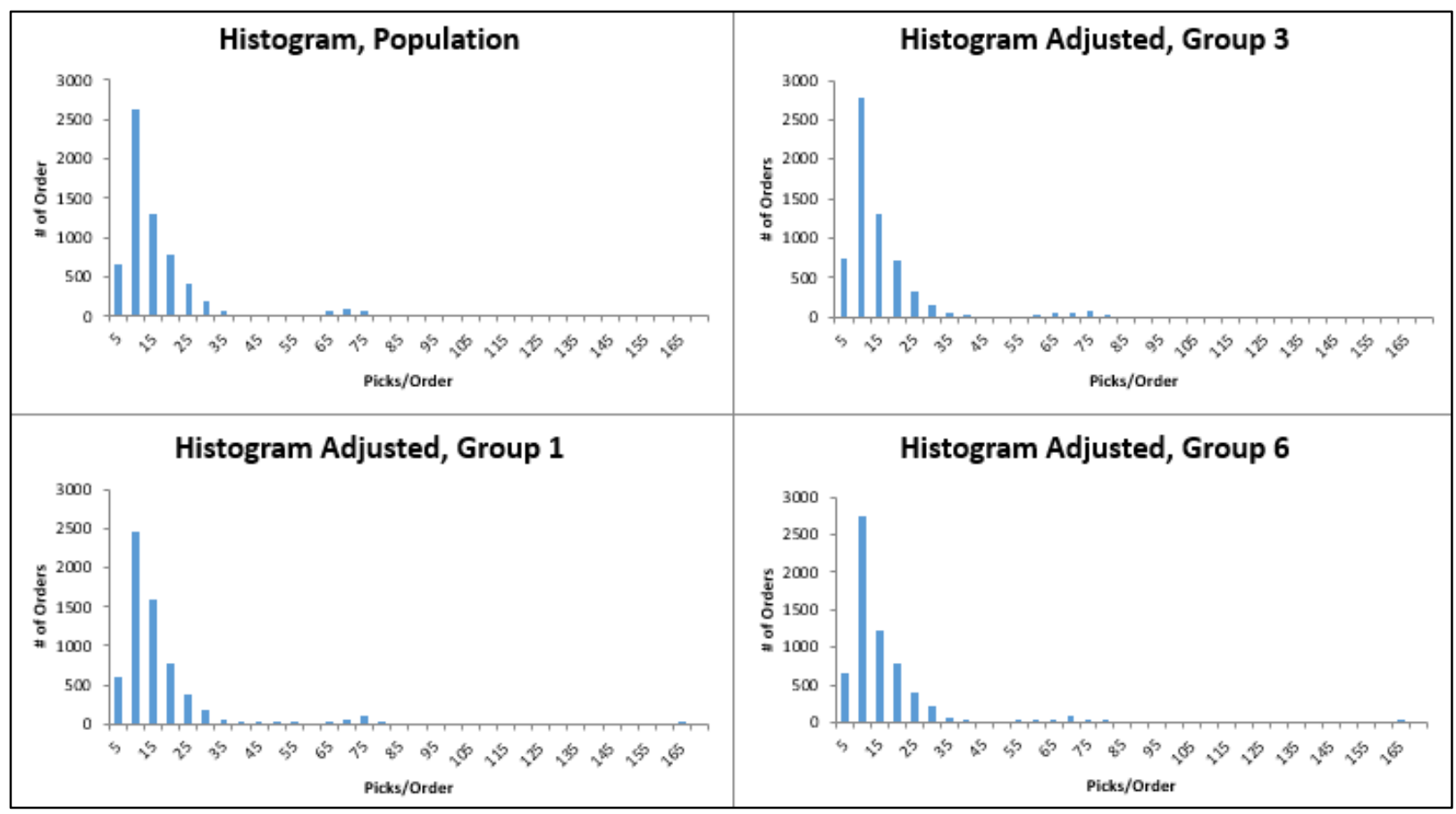

Figure 4. Histograms comparing picks/order distribution between 3 samples and the population data set

We consider this sufficient evidence to validate the samples of 800 and proceed with the experiment with them. Within the samples, \#6 contained the most SKUs (714), while also having the most similar picks/order to the population mean (14.19 to 14.23). The histograms between the population and sample 6 are nearly identical. Therefore we use sample 6 specifically, in the interest of using the most fair representation of the population.

\section{UNIT LOAD ADDITION}

In order to simulate the unit load activities incurred by order picking operations for the composite data input, a modification must be made to the input file. We must first calculate a realistic number of pallet depletions that incur unit load activities. To calculate the number of pallet depletions, $X_{D}, 3$ independent variables are defined:

- $\quad$ The random number of units each pallet contains at any given time, $R$ 
- The average number of max units/pallet across all SKUs, $M$

- The total picks for each SKU, $X_{P}$

The variable $R$ must exist to make our sample representative of a random portion of warehouse activity. At the start of any given day, a warehouse would typically contain pallets of random remaining unit counts. For $M$, we use data from a large, international distribution company with a warehouse storing an average of 29.8 units/pallet. We round this value to 30 .

$X_{P}$ is simply calculated by tallying the total number of picks across the 800 orders for each SKU. Each SKU's number of pallet depletions, $X_{D}$, over the 800 orders is defined by Equation 1 .

$$
X_{D}=\left\{\begin{array}{lll}
0 & \text { if } & X_{P}<R \\
n & \text { if } & (n-1) M+R \leq X_{P}<n M+R
\end{array}\right.
$$

Equation 1. Calculation of pallet depletions per SKU

This creates the pallet depletion count per SKU. We use a VBA program to create 2 unit load activities for each SKU for each of their respective depletions. Unit load replenishments are represented in the data file by individual orders with one SKU listed. This causes the travel path to become a unit load operation. For each SKU's replenishment movements, the unit load location visited will be the location that the SKU was specifically assigned to during the beginning of the layout evaluation. This assumes that each SKU in the forward pick area has reserve pallets in the storage rack levels above it. 
The original sample of 800 orders contained 11,351 rows (800 orders * 14.19 picks/order), and unit load operations increased the total to 12,111 for a difference of 760 unit load operations. This represents 380 pallet depletions that incurred 380 forward-pick area replenishments and 380 pallet receiving operations. This number of replenishments aligns with the calculation for $\alpha$, equal to $\frac{14.19}{30} \frac{(\text { Picks } / \text { order })}{(\text { Units } / \text { Pallet })}=0.473$. The 14.19 Picks/Order comes from the Mean picks per Order for sample 6 in Table 1. Therefore, $2 \alpha$ replenishment activities per order should be $2(0.473) \approx 0.95$, or nearly 1 unit load operation incurred per order picking tour. With 800 orders, $0.95 \times 800=760$ incurred unit load operations, which is exactly how many were added to the input data file. 


\section{RESULTS}

The primary goal of our experiment is to determine if using consideration for both unit load and order picking when optimizing aisle design yields greater labor improvements from standard layouts than previously determined with just consideration for order picking. Therefore, we define 3 different types of layouts to be generated: layouts generated by inputting order picking data (Figures 5-10), layouts generated by inputting the order picking data with unit load additions (Figures 11-16), and layouts manually created with the program (Figures 17-22).

We use 6 unique seeds for generating layouts with order picking and composite input data. We use the same 6 seeds for both layout types, producing 12 layouts in total. The different seeds are for the random number generator that creates the initial random layout. The initial optimal layouts found during program run time is typically changed significantly by different seeds before iterations of mutation and selection occur.

For the third layout type, we use 4 known layouts: 3 standard warehouses with 0 , 1 and 2 centered cross aisles and one warehouse with parallel storage aisles and diagonal cross aisles at 45 degrees, connecting to the I/O point. These are shown in Figures 17-20. 


\section{LAYOUTS OPTIMIZED FOR ORDER PICKING ONLY (TYPE 1), A-F}

Note: the colors represent the relative demand of the storage locations. The colors indicate, in order of high to low demand: Red, yellow, green, blue, purple.

Note: the black dot in the layout represents the I/O point.

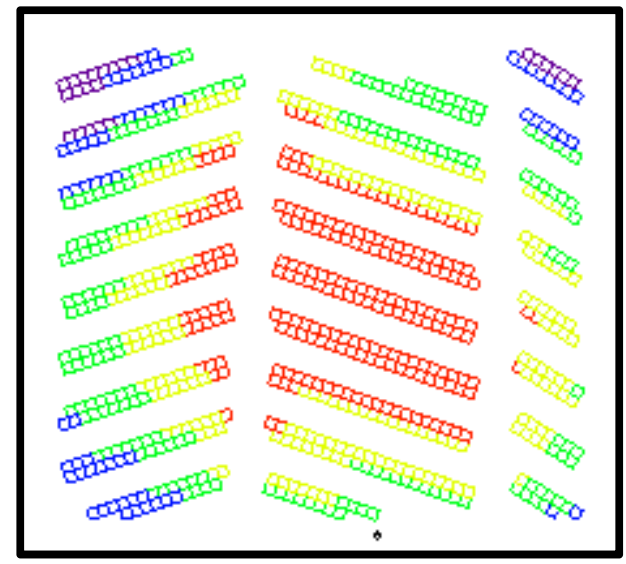

Figure 5. Layout type 1, A

Average Travel Distance: 524.1

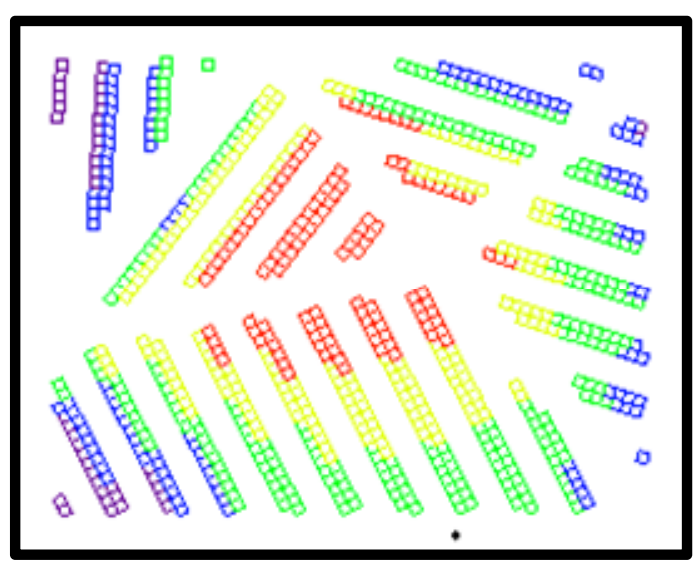

Figure 6. Layout type 1, B

Average Travel Distance: 527.9 


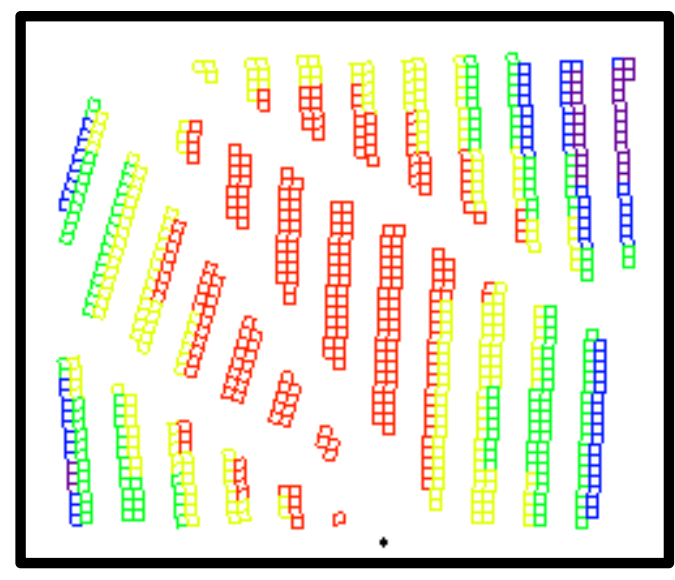

Figure 7. Layout type 1, C

Average Travel Distance: 517.1

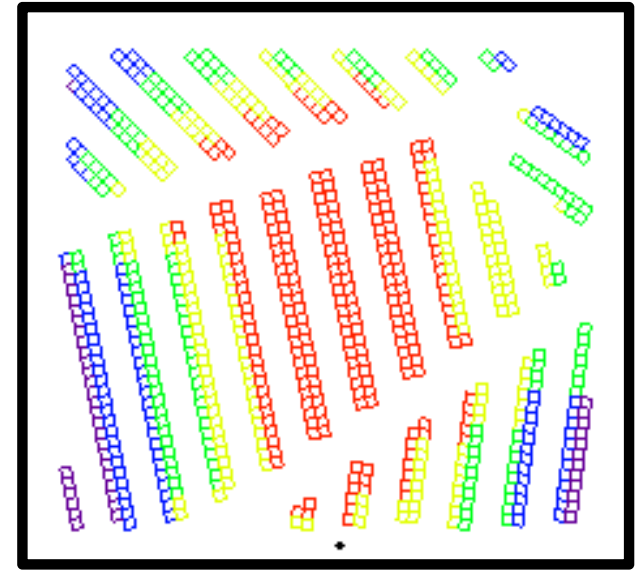

Figure 8. Layout type 1, D

Average Travel Distance: 495.7

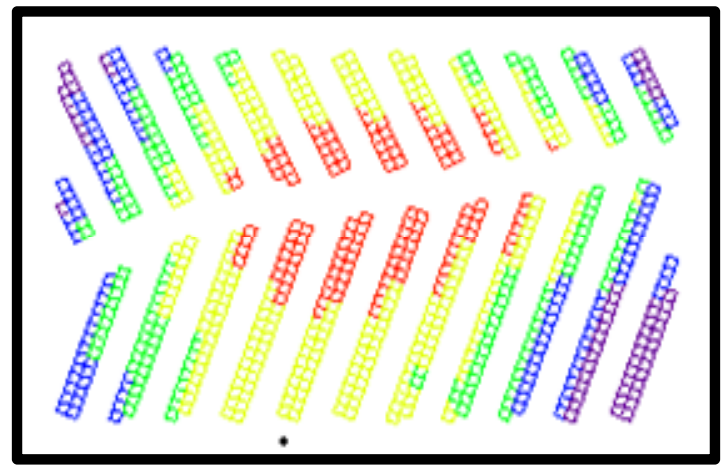

Figure 9. Layout type 1, E

Average Travel Distance: 524 


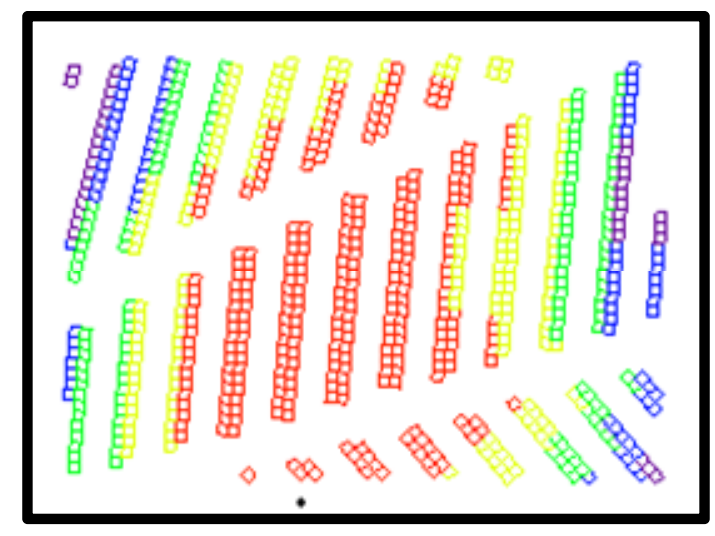

Figure 10. Layout type 1, F

Average Travel Distance: 521.5

\section{LAYOUTS OPTIMIZED FOR UNIT LOAD AND ORDER PICKING (TYPE 2), A-F}

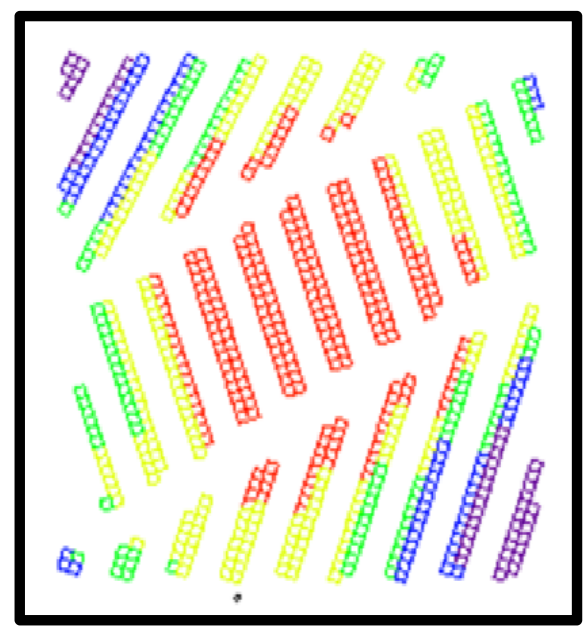

Figure 11. Layout type 2, A

Average Travel Distance: 499 


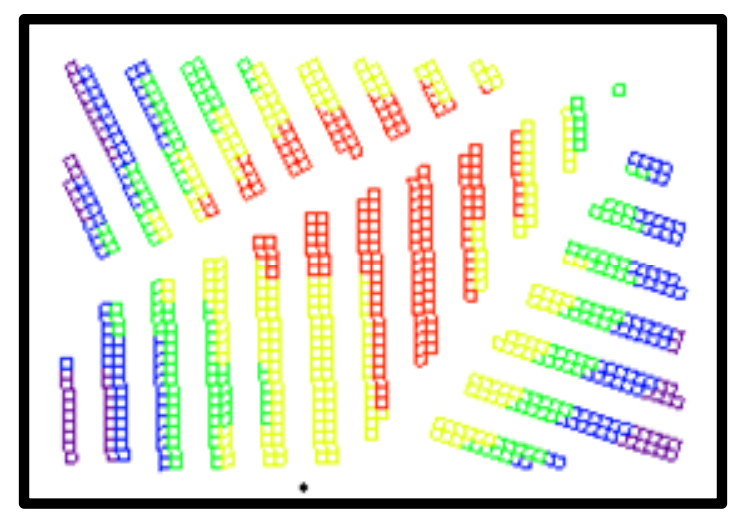

Figure 12. Layout type 2, B

Average Travel Distance: 494

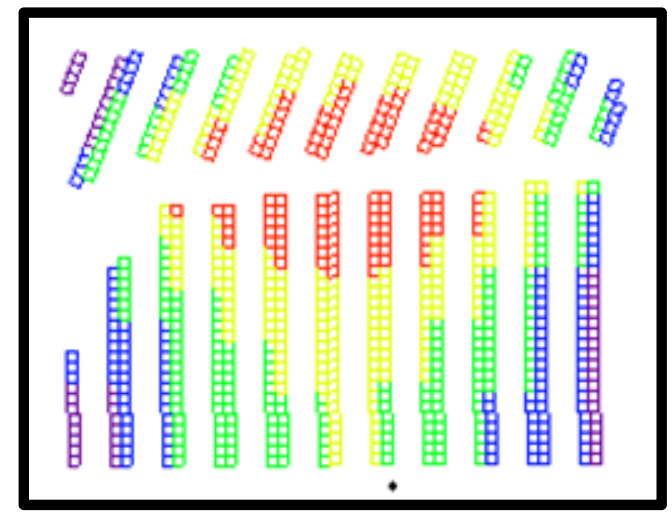

Figure 13. Layout type 2, C

Average Travel Distance: 510.5

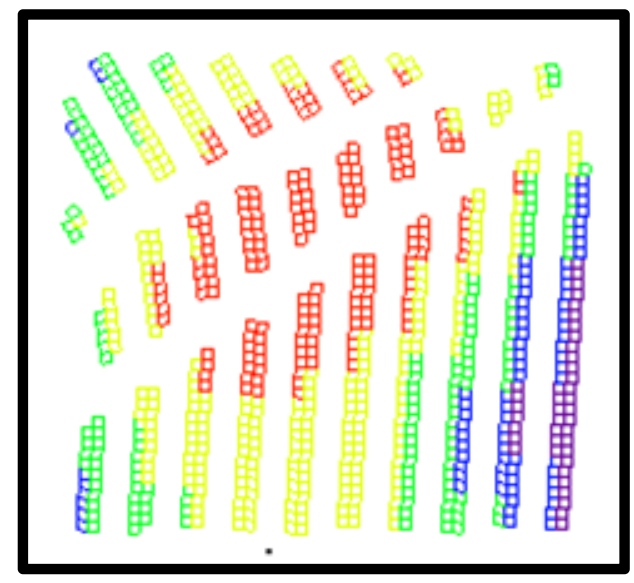

Figure 14. Layout type 2, D

Average Travel Distance: 510.3 


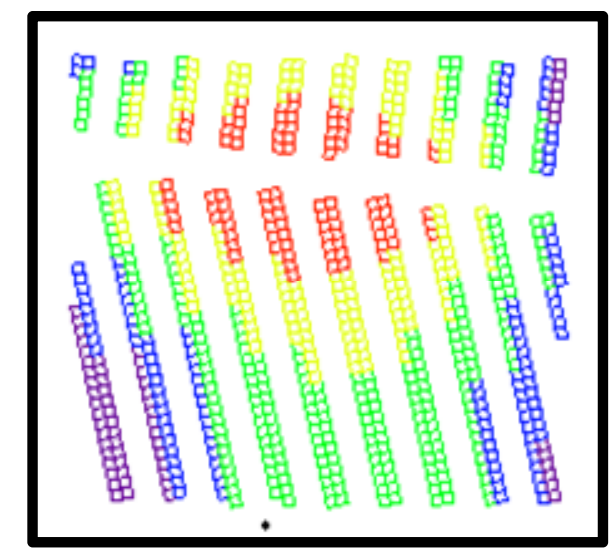

Figure 15. Layout type 2, E

Average Travel Distance: 508.2

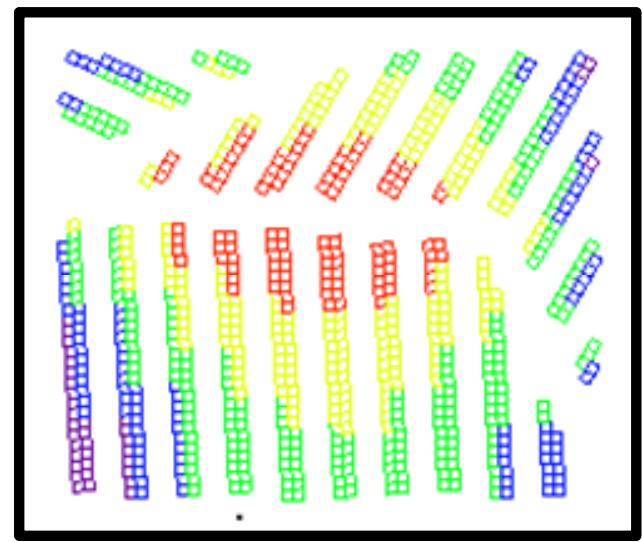

Figure 16. Layout type 2, F

Average Travel Distance: 505.7

MANUALLY CREATED LAYOUTS (TYPE 3), A-D

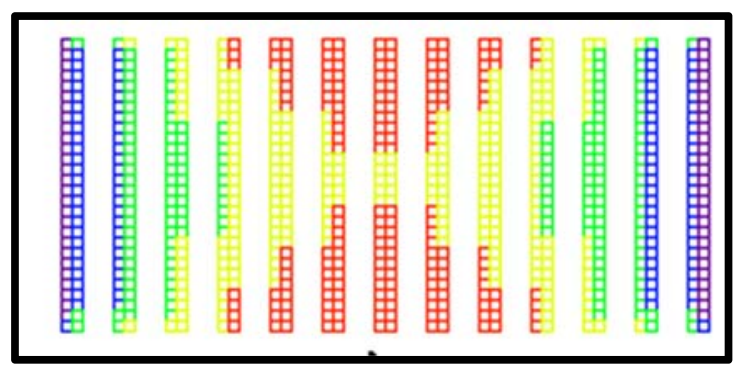

Figure 17. Layout type 3, A

Average Travel Distance: 573.4 


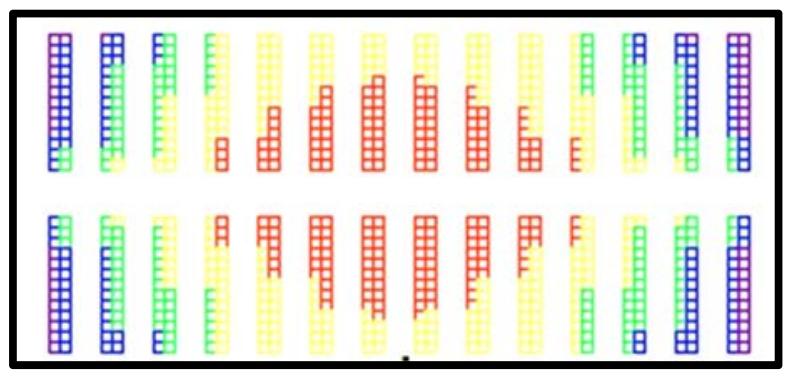

Figure 18. Layout type 3, B

Average Travel Distance: 524.7

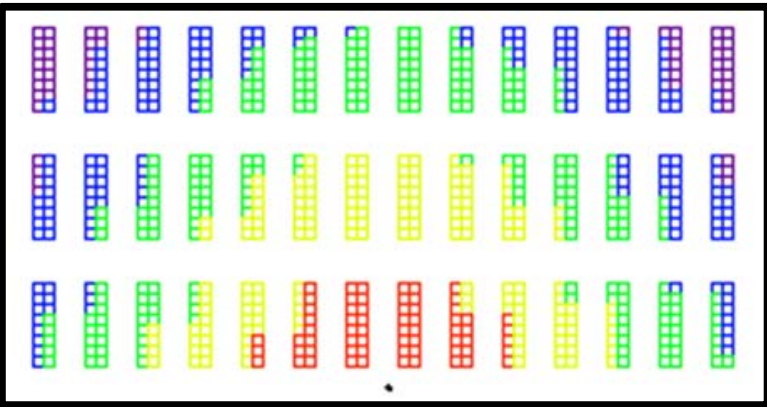

Figure 19. Layout type 3, C

Average Travel Distance: 475.7

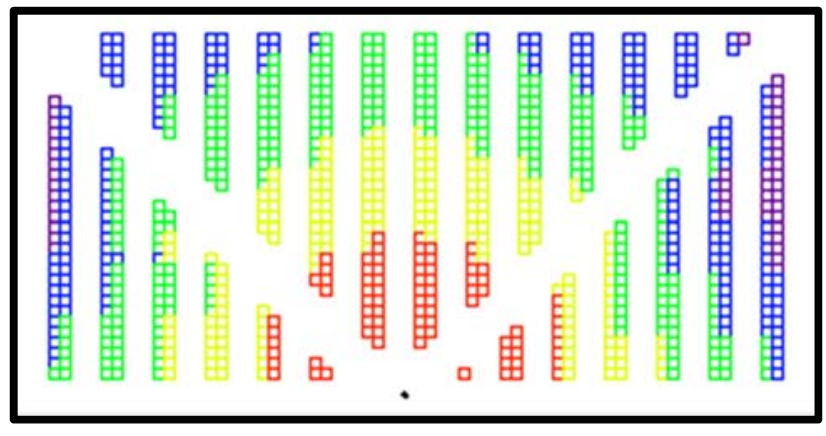

Figure 20. Layout type 3, D

Average Travel Distance: 578.9 


\section{ANALYSIS}

If order picking warehouses realistically must consider unit load labor in addition to their order picking operations, then all layouts must be compared by their travel distance using the composite unit load and order picking data input. The layouts produced by just order picking data are consequently evaluated using the composite data after their generation. The organization of these 3 layout types being evaluated by two data types is illustrated in Table 2. Values $X_{1}$ through $Y_{3}$ represent average travel distance calculated by the program with the given data input $(\mathrm{X}, \mathrm{Y})$ and the given layout group (1-3).

\begin{tabular}{|c|c|c|c|}
\hline \multirow{2}{*}{$\begin{array}{c}\text { Average Travel } \\
\text { Distance }\end{array}$} & \multicolumn{3}{|c|}{ Layout Type } \\
\cline { 2 - 4 } & $\begin{array}{c}\text { Evaluated } \\
\text { in Layout } \\
\text { Optimized } \\
\text { for Order } \\
\text { Picking }\end{array}$ & $\begin{array}{c}\text { Evaluated in } \\
\text { Layout } \\
\text { Optimized for } \\
\text { Order Picking } \\
\text { and Unit Load }\end{array}$ & $\begin{array}{c}\text { Evaluated in } \\
\text { Manually } \\
\text { Designed } \\
\text { Layouts }\end{array}$ \\
\hline $\begin{array}{c}\text { Order Picking Data } \\
\text { Input }\end{array}$ & $\mathbf{X}_{\mathbf{1}}$ & $\mathbf{X}_{\mathbf{2}}$ & $\mathbf{X}_{\mathbf{3}}$ \\
\hline $\begin{array}{c}\text { Composite Order } \\
\text { Picking and Unit Load } \\
\text { Data Input }\end{array}$ & $\mathbf{Y}_{\mathbf{1}}$ & $\mathbf{Y}_{\mathbf{2}}$ & $\mathbf{Y}_{\mathbf{3}}$ \\
\hline
\end{tabular}

Table 2. Organization of Initial Program Outputs

$\mathrm{X}_{1}$ through $\mathrm{Y}_{2}$ each have 6 values from the 6 seeds, and $\mathrm{X}_{3}$ and $\mathrm{Y}_{3}$ each have 4 values from the 4 manually created layouts. The matrix for these values is displayed in Table 3. 


\begin{tabular}{|c|c|c|c|c|c|c|c|c|}
\hline \multirow{3}{*}{\multicolumn{2}{|c|}{$\begin{array}{c}\text { Average Travel } \\
\text { Distance }\end{array}$}} & \multicolumn{4}{|c|}{ Input-Layout Combination } & \multirow{3}{*}{$\begin{array}{c}\text { Standard } \\
\text { Layout }\end{array}$} & \multirow{2}{*}{\multicolumn{2}{|c|}{ Input }} \\
\hline & & \multicolumn{2}{|c|}{ Layout Type 1} & \multicolumn{2}{|c|}{ Layout Type 2} & & & \\
\hline & & $\mathrm{X} 1$ & Y1 & $\mathrm{X} 2$ & Y2 & & $X$ & $\mathrm{Y}$ \\
\hline \multirow{6}{*}{ Seed } & A & 752.8 & 524.1 & 742.3 & 499 & A & 838.8 & 573.4 \\
\hline & $\mathrm{B}$ & 758.1 & 527.9 & 748 & 494 & $\mathrm{~B}$ & 759 & 524.7 \\
\hline & $\mathrm{C}$ & 735.2 & 517.1 & 752.6 & 510.5 & $\mathrm{C}$ & 692.8 & 475.7 \\
\hline & $\mathrm{D}$ & 748 & 495.7 & 805.9 & 510.3 & $\mathrm{D}$ & 867.9 & 578.9 \\
\hline & $\mathrm{E}$ & 747.6 & 524 & 781.3 & 508.2 & & & \\
\hline & $\mathrm{F}$ & 743.7 & 521.5 & 767.8 & 505.7 & & & \\
\hline & Average: & 747.57 & 518.38 & 766.32 & 504.62 & & & \\
\hline
\end{tabular}

Table 3. Matrix of Average Travel Distance Values with Data Input, Layout and Seed

A noticeable feature of these outputs is that the X columns are significantly larger than the output of the Y columns. This makes sense because the Y columns include outputs from inputs with 760 unit load orders, which are shorter on average than order picking tours averaging 14.19 picks per tour. These relatively short unit load operations drastically lower the average order-pick time calculated by the program.

The following two inequalities must be true if the layout produced by the program is significantly affected by the inclusion of unit load operations: $\bar{Y}_{2}<\bar{Y}_{1}$ and $\bar{X}_{1}<\bar{X}_{2}$. The first inequality confirms that the layouts produced from optimizing with additional unit load operations are an improvement over layouts produced without them. This inequality is true for our experiment, with $\bar{Y}_{2}=504.62$ and $\bar{Y}_{1}=518.38$. This is an average of $2.65 \%$ travel time improvement for composite data when the layout is optimized for the composite data.

The latter relationship, $\bar{X}_{1}<\bar{X}_{2}$, confirms the same hypothesis is true for data without unit load operations. Both relationships must be true if the results are valid, 
because the layout produced for a given data set should be better optimized for that data specifically. This is true again for our experiment, with $\bar{X}_{1}=747.57$ and $\bar{X}_{2}=766.32$. This is an average of $2.44 \%$ travel time improvement for order picking data when the layout is optimized for order picking data alone.

The fact that both layout types can be simultaneously more efficient for the data by which they were optimized prompts further analysis in the section Unit Load Vs. Order Picking Distance.

\section{COMPARISON TO STANDARD}

In this section, we revisit our primary question: can significant improvements from standard aisle design can be found when unit load replenishments are included in optimization?

The 3 layouts with the least travel distance are layout type 1, seed D (Figure 8), layout type 2, seed B (Figure 12) and standard layout 3, with 2 cross aisles (Figure 19). The standard warehouse design $\mathrm{C}$ with 2 cross aisles has the lowest average travel distance for both data inputs. These layouts are compared in Table 4. The two generated layouts are compared side-by-side for comparison as well in Figure 21.

The initial results show that the standard layout is superior. Before reaching a final conclusion, there are a number of manual adjustments to be made to the general layout to fix attributes unsuitable for production. There are storage aisle and cross aisle angles in the generated layouts that are unsuitable for implementation. Rectifying these angles to form 45 and 90 degrees may improve the fitness value while making the layout more feasible. 


\begin{tabular}{|c|c|cc|}
\hline \multicolumn{2}{|c|}{$\begin{array}{c}\text { Average Travel } \\
\text { Distance }\end{array}$} & \multicolumn{2}{|c|}{ Average Travel Distance } \\
\cline { 3 - 4 } \multicolumn{2}{|c|}{} & $\begin{array}{c}\text { Order Picking } \\
\text { Data }\end{array}$ & Composite Data \\
\hline \multirow{3}{*}{ Layout } & $1-\mathrm{D}$ & 748 & 495.7 \\
& $2-\mathrm{B}$ & 748 & 494 \\
& $3-\mathrm{C}$ & 692.8 & 475.7 \\
\hline
\end{tabular}

Table 4. Comparison of 3 Best Designs

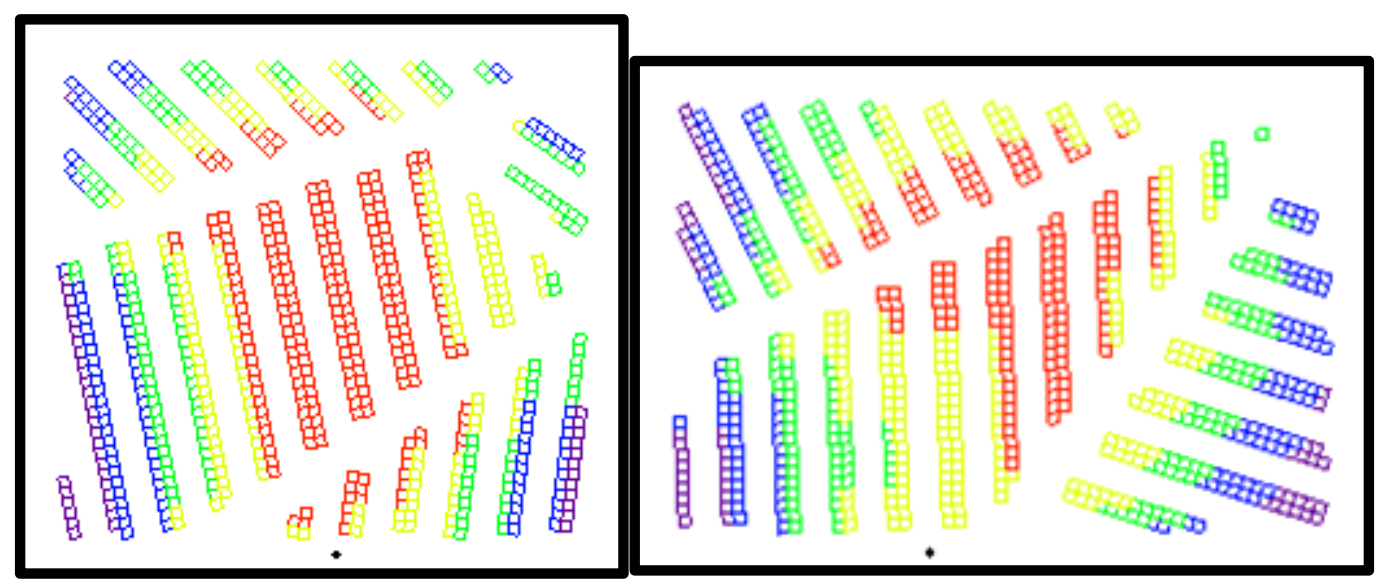

Figure 21. Visual comparison of the best 2 generated designs, layouts 1-D and 2-

$\mathrm{B}$, respectively

The two layouts in Figure 21 (1-D and 2-B) have nearly identical travel distance, and highly similar design. The designs in Figures 10, 11 and 14 contain design attributes that could also be related. If several program executions with different initial layouts converge towards similar attributes in the end of the program run time then it is reasonable to believe that these attributes are desirable, or generally effective in reducing total travel distance for the order data input. In this case, we can observationally define these potentially effective attributes as 2 cross aisles, with one connecting to the West 
side and North-Eastern corner, and another connecting to the Southern side and East side or North-Eastern corner.

After testing a multitude of combinations of the attributes of both layouts, one result neared the travel distance value provided by the standard. The cross aisle placement of layout 1-D (without the third vestigial fluke cross aisle in the North Eastern corner), the storage aisle angles similar to those in layout 2-B produced the best result out of the manual manipulations. The resulting average travel distance was 475.8 . This value is approximately equal to the travel distance associated with the standard 2 cross aisle design.

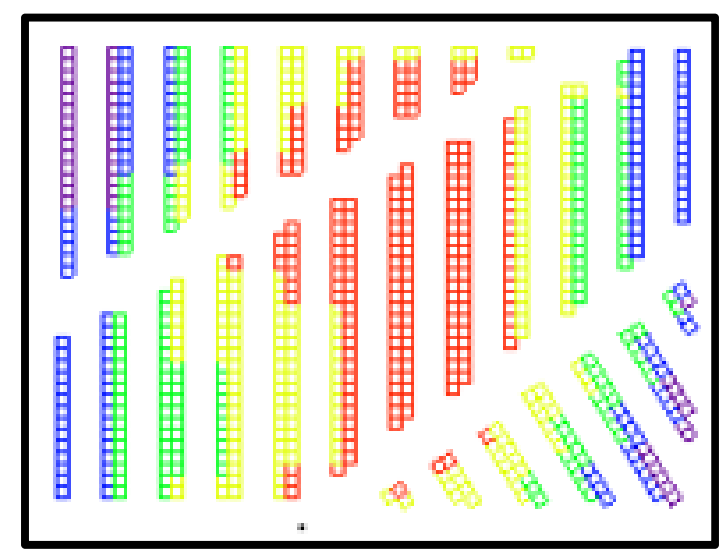

Figure 22. Result of manually modifying attributes of layouts 1-D and 2-B The result of the exercise illustrates two important points. The first point is that we found no evidence that there exists an improvement upon the standard warehouse with respect to average travel distance per order for order picking operations and their incurred unit load operations. The best results from the program presented travel distances $3.7 \%$ greater than a standard 2 cross aisle design. The best result of manual adjustments on these results shows no improvement either. 
The second point is that the program used in this work can become stuck in local optima. The fact that our manual manipulation of layout attributes decreased average distance traveled from 494 to 475.8 , a 3.68\% decrease, indicates that the outputs of this program cannot conclusively answer the question asked in this research. This does not mean any observations or even any potentials discovered with the program are invalid, but rather that whatever minimum travel distance is found, cannot be proven as the absolute minimum travel distance possible. Additionally, the question must be asked: why doesn't the program produce the standard layouts? 


\section{UNIT LOAD VS. ORDER PICKING}

It is shown in the Output Analysis section that evaluating the order picking data in the layouts produced by the optimization of the order picking data (Layout type 1) produces $2.44 \%$ better results than evaluating it in layouts optimized for the composite data (Layout type 2). Conversely, the composite data has $2.65 \%$ better results in the layouts optimized for it. If the order picking data performs better in type 1 layouts, then type 1 layouts are likely better for order picking operations. If the data including unit load and order picking operations perform better in type 2 layouts, and type 1 layouts are better for order picking operations, then type 2 layouts must be better for unit load operations. Further exploration proves that this is true.

Multiplying the average travel distance of data evaluated in a layout by the number of orders reveals the total travel distance. Subtracting the total travel distance of a composite input by the total travel distance of the order picking input yields the total travel distance of unit load operations, which can then be used to calculate the average unit load travel distance. Table 5 illustrates the difference between the unit load and order picking travel distance of each layout. 


\begin{tabular}{|c|c|c|c|c|c|c|}
\hline \multirow[b]{2}{*}{ Seed } & \multicolumn{2}{|c|}{$\begin{array}{c}\text { Average Order } \\
\text { Picking Distance } \\
\end{array}$} & \multicolumn{2}{|c|}{$\begin{array}{c}\text { Average Unit-Load } \\
\text { Distance }\end{array}$} & \multicolumn{2}{|c|}{ Average Distance } \\
\hline & $\begin{array}{l}\text { Layout } \\
\text { Type } 1\end{array}$ & $\begin{array}{l}\text { Layout } \\
\text { Type } 2\end{array}$ & $\begin{array}{l}\text { Layout } \\
\text { Type } 1\end{array}$ & $\begin{array}{l}\text { Layout } \\
\text { Type } 2\end{array}$ & $\begin{array}{l}\text { Layout } \\
\text { Type } 1\end{array}$ & $\begin{array}{l}\text { Layout } \\
\text { Type } 2\end{array}$ \\
\hline $\mathrm{A}$ & 752.8 & 742.3 & 283.4 & 242.9 & 524.1 & 499.0 \\
\hline B & 758.1 & 748.0 & 285.6 & 226.6 & 527.9 & 494.0 \\
\hline $\mathrm{C}$ & 735.2 & 752.6 & 287.5 & 255.7 & 517.1 & 510.5 \\
\hline $\mathrm{D}$ & 748.0 & 805.9 & 230.1 & 199.1 & 495.7 & 510.3 \\
\hline $\mathrm{E}$ & 747.6 & 781.3 & 288.6 & 220.7 & 524.0 & 508.2 \\
\hline $\mathrm{F}$ & 743.7 & 767.8 & 287.6 & 229.8 & 521.5 & 505.7 \\
\hline Average: & 747.6 & 766.3 & 277.1 & 229.1 & 518.4 & 504.6 \\
\hline
\end{tabular}

Table 5. Order Picking Vs. Unit Load Average Travel Distance

Note: Coloring is depending on value, and relative to the distance type (Order Picking,

Unit-Load, Average) in descending order: Red - Yellow - Green

Table 5 shows that type 2 layouts have much smaller unit load travel distances on average, with an improvement of $17.3 \%$ over type 1 layouts. Despite this, type 1 layout only have a $2.4 \%$ improvement in order picking travel distance. Additionally, the incorporation of unit load operations during optimization for type 2 layouts created a $2.7 \%$ improvement overall. It is apparent by this information that a large improvement for unit load operations can be made with relatively little cost to order picking operations.

If a warehouse has a large ratio of unit load to order picking operations (a large value of $2 \alpha$ ), then the tradeoff of reducing unit load travel distance by approximately $17.3 \%$ for approximately $2.4 \%$ increase in order picking travel distance may be worthwhile. Also, analysis of unit load and order picking travel distance separately may reveal additional information for decision making. 


\section{CONCLUSION}

In this work, we discussed the differences between order-picking and unit-load operations and how consideration of both is necessary for optimal aisle design. We then framed the current lack of literature regarding this consideration of order picking and unit load data in tandem. Importantly, we create and use a metric, $\alpha$, to define the relationship between order picking operations and their inherently incurred unit load operations. After

introducing the program for layout optimization and validating our sample of data used as the input, we created 6 layouts from order picking data and 6 from order picking and unit load data. The groups were compared to each other, and both were compared to a third group of known layouts that were manually designed. We present the outputs in terms of a fitness function, average travel distance per order, and as visual representations.

None of the generated layouts were improvements from the standard 2 cross aisle warehouse in layout group 3. Further exploration of the best generated layouts in our experiments reveals no further evidence that improvements from the standard warehouse exist. However, it is also revealed that the program may not be able to provide the answers sought in our work. Manual reconfiguration of a generated layout yielded large improvements for travel distance, showing that the program may not be able to find optimum solutions on its own. 
Three primary benefits come from our work for the scientific literature of this topic. Firstly, we address the need unit-load operations belong in order-picking warehouse design problems. Second, we demonstrate a method of defining the relationship between the two labor types, order picking and unit load. Lastly, we demonstrate an imbalanced trade-off between the reduction of travel distance of order picking and unit load operations. We hope to see consideration of this information in future aisle design research, and the nature of these operational types explored further. 


\section{REFERENCES}

Bassan, Y., Roll, Y. and Rosenblatt, M. J. 1980. Internal layout design of a warehouse. IIE Transactions, 12(4): 317-322.

Berglund, P., \& Batta, R. (2012). Optimal placement of warehouse cross-aisles in a picker-to-part warehouse with class-based storage. IIE Transactions, 44(2), 107-120.

Berry, J. R. 1968. Elements of warehouse layout. International Journal of Production Research, 7(2): 105-121.

Bortolini, M., Faccio, M., Gamberi, M., \& Manzini, R. (2015). Diagonal cross-aisles in unit load warehouses to increase handling performance. International Journal of Production Economics, 170, 838-849.

Bortolini, M., Faccio, M., Ferrari, E., Gamberi, M., \& Pilati, F. (2019). Design of diagonal cross-aisle warehouses with class-based storage assignment strategy. The International Journal of Advanced Manufacturing Technology, 100(9-12), 2521-2536.

Francis, R. L. 1967. On some problems of rectangular warehouse design and layout. The Journal of Industrial Engineering, 18(10): 595-604.

Gue, K. R. and Meller, R. D. (2009). Aisle configurations for unit-load warehouses. IIE Transactions on Design \& Manufacturing, 41(3):171-182. 
Hackman, S. T., Rosenblatt, M. J., \& Olin, J. M. (1990). Allocating items to an automated storage and retrieval system. IIE transactions, 22(1), 7-14.

Jarvis, J. M. and McDowell, E. D., 1991, Optimal product layout in an order picking warehouse. IIE Transactions, 32, 93-102.

John A. White (1972) Optimum Design of Warehouses Having Radial Aisles 1, AIIE Transactions, 4:4, 333-336, DOI: 10.1080/05695557208974871

Kallina, C. and Lynn, J. 1976. Application of the cube-per-order index rule for stock location in a distribution warehouse. Interfaces, 7: 37-46.

Matson, J. O., \& White, J. A. (1981). Storage system optimization (No. PDRC-81-09). GEORGIA INST OF TECH ATLANTA PRODUCTION AND DISTRIBUTION RESEARCH CENTER.

Ozden, S. G. (2017). A Computational System to Solve the Warehouse Aisle Design Problem.

Öztürkoğlu, Ö., \& Hoser, D. (2019). A discrete cross aisle design model for orderpicking warehouses. European Journal of Operational Research, 275(2), 411-430.

Pohl, L. M., Meller, R. D., \& Gue, K. R. (2009). Optimizing fishbone aisles for dualcommand operations in a warehouse. Naval Research Logistics (NRL), 56(5), 389-403.

Ratliff, H. D. and Rosenthal, A. S. 1983. Order-picking in a rectangular warehouse: a solvable case of the traveling salesman problem. Operations Research, 31(3): 507-521.

Roberts, S. D. (1968). Warehouse size and design. 
Vaughan, T. S. (1999). The effect of warehouse cross aisles on order picking efficiency. International Journal of Production Research, 37(4), 881-897. 